\title{
How a Rapid Modal Convergence into a Universal Automated Taxi Service Could be the Future for Local Passenger Transport
}

\author{
Marcus P Enoch \\ School of Civil and Building Engineering, \\ Loughborough University, \\ Leicestershire, \\ LE11 3TU, UK. \\ Tel: +44 (0)1509 223408. \\ Email: m.p.enoch@lboro.ac.uk.
}

\begin{abstract}
The world is changing rapidly. Yet a common assumption is that cars, buses and taxis will remain the dominant local passenger transport modes in the coming decades. This concept paper draws on literature sources and on discussions with industry stakeholders to look anew at the local passenger transport sector in the light of broader societal trends to suggest an alternative future, and to offer insights to practitioners and policy makers.

The paper finds that the traditional modes of car, bus and taxi are slowly beginning to lose market share to intermediate modes such as shared taxis, lift sharing schemes, DRT services and car clubs whilst numerous technological and market trends are combining to accelerate this process of 'modal convergence'. Taken together, these trends could revolutionise how we move about, with one possible outcome being the emergence of a single dominant passenger mode of an automated universal taxi system or dial-a-pod.
\end{abstract}

Keywords: driverless vehicles, autonomous transport system, transport planning scenario, transport policy futures, technological-cycles innovation model.

\section{Introduction}

Morris (2007) details how the horse displaced by the motor vehicle within a period of only a very few years around the world in the early years of the $20^{\text {th }}$ century. In particular, he comments on the associated knock on implications whereby the issues generated by intensive use of the horse (fuel supply, land use, waste products, congestion, accidents, noise, air pollution and the resultant health effects) were 'solved', only to be reincarnated in a different (and arguably more virulent) form. Given the significant societal changes now underway, one wonders whether a similar revolution is about to occur in the way in which local passenger transport is used and supplied, and about the possible side effects this time round.

This paper conceptualises a possible future for the local passenger transport system, in light of current technological and market trends. Specifically, it outlines the 'traditional' local passenger transport landscape; examines the emergence of a variety of intermediate modes; details the factors that are pushing the development of these modes; explores a possible future of how the local transport system may evolve as a result; and draws implications for policy makers and practitioners.

Methodologically, it draws on a review of academic and grey literature, and on ideas that emerged from discussions undertaken with fellow industry observers and representatives from government agencies, transport operators, and other interested parties who participated in four events designed to understand how such intermediate modes may develop in the future. These were: the DRT Workshop, (Summer Conference of the Association of Transport Coordinating Officers, Birmingham, 21 June 2012 ${ }^{1}$ ); Car Clubs and Car Rental Seminar, (RAC Foundation, London, 12 July $2012^{2}$ ); Future of Journey Sharing Seminar, (Carplus, London, 25 April 2013 ${ }^{3}$ ); Company Cars, Costs and the Climate Seminar, (British Vehicle Rental and Licensing Association, London, 18 July

\footnotetext{
${ }^{1}$ See http://www.atco.org.uk/component/eventlist/details/24-summer-conference-2012 for details of the event.

${ }^{2}$ For conference outputs see Lytton and Posten (2012).

${ }^{3}$ See http://www.carplus.org.uk/managing-and-reporting-data-in-the-ride-share-sector/ for details of the event.
} 
$\left.2013^{4}\right)$. Unfortunately from a research perspective, these events proceeded under 'Chatham House' rules meaning an individual's comments cannot be attributed - hence the 'discussion paper' format.

Such a paper is useful for two reasons. Firstly, while much useful work has been conducted on the future development of individual modes (and groups of modes) within the local transport system (e.g. Barth and Shaheen (2002), Shaheen and Cohen (2013), and Millard Ball (2005) on car clubs; Enoch et al, (2004), and Davison et al (2012) on DRT schemes), no view was taken as to how all of the different elements might evolve in the context of the local transport system as a whole. Second, practitioners and policy makers must make decisions now that will have significant implications for the future, but most of the academic literature currently seems to make the assumption that there will be no fundamental change in how transport is delivered and consumed (e.g. Zmud et al, 2013). This paper aims to address both of these gaps.

\section{The traditional local passenger transport landscape}

According to Vuchic (2007), local passenger transport modes can be categorised as being 'common carrier' (user rents a seat/space), 'paratransit' (user rents the vehicle), or 'private' (where the user owns the vehicle), and each type has particular characteristics. Table 1 sets these out for the most typical examples in each category, i.e. the bus, taxi and car.

\begin{tabular}{|l|l|l|l|}
\hline & Common carrier & Paratransit & Private transport \\
\hline $\begin{array}{l}\text { Typical example } \\
\text { modes }\end{array}$ & Bus & Taxi & Car \\
\hline Characteristics & $\begin{array}{l}\text { User rents a seat and } \\
\text { is driven to } \\
\text { destination. }\end{array}$ & $\begin{array}{l}\text { User rents a vehicle } \\
\text { and is driven to } \\
\text { destination. }\end{array}$ & $\begin{array}{l}\text { User owns a vehicle } \\
\text { and is required to } \\
\text { drive oneself. }\end{array}$ \\
\hline $\begin{array}{l}\text { Optimal operating } \\
\text { conditions }\end{array}$ & $\begin{array}{l}\text { Best service level } \\
\text { provided in areas } \\
\text { where demand is high. }\end{array}$ & $\begin{array}{l}\text { Supply usually } \\
\text { responsive to level of } \\
\text { demand. }\end{array}$ & $\begin{array}{l}\text { Best service level } \\
\text { provided in areas } \\
\text { where demand is low. }\end{array}$ \\
\hline Strengths & $\begin{array}{l}\text { Cost to users usually } \\
\text { relatively low. }\end{array}$ & $\begin{array}{l}\text { Service quality is high. } \\
\text { Small vehicle; largely } \\
\text { on demand and door- } \\
\text { to-door; exclusive use. }\end{array}$ & $\begin{array}{l}\text { Service quality is very } \\
\text { high. Small vehicle; on } \\
\text { demand and door-to- } \\
\text { door; exclusive use. }\end{array}$ \\
\hline Weaknesses & $\begin{array}{l}\text { Service quality is low. } \\
\text { Large vehicle; } \\
\text { scheduled and often } \\
\text { indirect and/or } \\
\text { infrequent services; } \\
\text { shared usage. }\end{array}$ & $\begin{array}{l}\text { Cost to users very } \\
\text { high. }\end{array}$ & $\begin{array}{l}\text { High up front cost to } \\
\text { buy the vehicle but } \\
\text { fairly low per trip cost. }\end{array}$ \\
\hline
\end{tabular}

Table 1: Modal characteristics of the bus, taxi and private car (compiled from information in Vuchic, 2007, chapter 2).

From Table 1 each of these 'traditional' modes exhibits advantages and disadvantages. So, the bus is cheap but poor quality; taxis are high quality but pricey; and although the car is both relatively cheap and high quality, a user needs to own the vehicle and also be physically and legally able to drive it.

Of course other modes too are important - particularly rail-based public transport in larger urban areas - and there are policy and practitioner implications that arise from this distinction which are referred to later in this article. However, for the majority of people in the majority of locations, rail is generally only an option for longer journeys. And where this is not the case, as in London for example, one might argue that from a user perspective the Underground (a metro service) and local rail services operate in almost the same manner as an equivalent bus service with broadly comparable characteristics from the user perspective.

\section{The rise of intermediate modes}

In response to these weaknesses, a number of 'intermediate' modes are emerging. Demand responsive transport (DRT) schemes improve journey quality for bus users at a still low cost, while

\footnotetext{
${ }^{4}$ See http://www.bvrla.co.uk/news/press-release/workshop-explores-greater-government-and-fleetindustry-co-operation for a press release of the event.
} 
shared taxis schemes provide (almost) taxi levels of service quality for a lower fare. Similarly, rental/hire car organisations and car club schemes provide a car to someone who does not then need to buy it, while lift sharing schemes remove the need for car users to be able to drive. Most recently, Transportation Network Companies (TNCs) such as Uber Taxi and Lyft are now offering almost taxi levels of service through 'peer to peer' models of dynamic liftsharing operation, whereby ordinary drivers are giving people lifts in exchange for fares (Chernick and Shaheen, 2014).

Table 2 plots these and other modes, and their characteristics. Interestingly some, though not all, of these intermediate modes first appeared several decades ago (see Nutley, 1988), but it is only in recent years that many of these have begun to enter what could be termed as being the mainstream. 


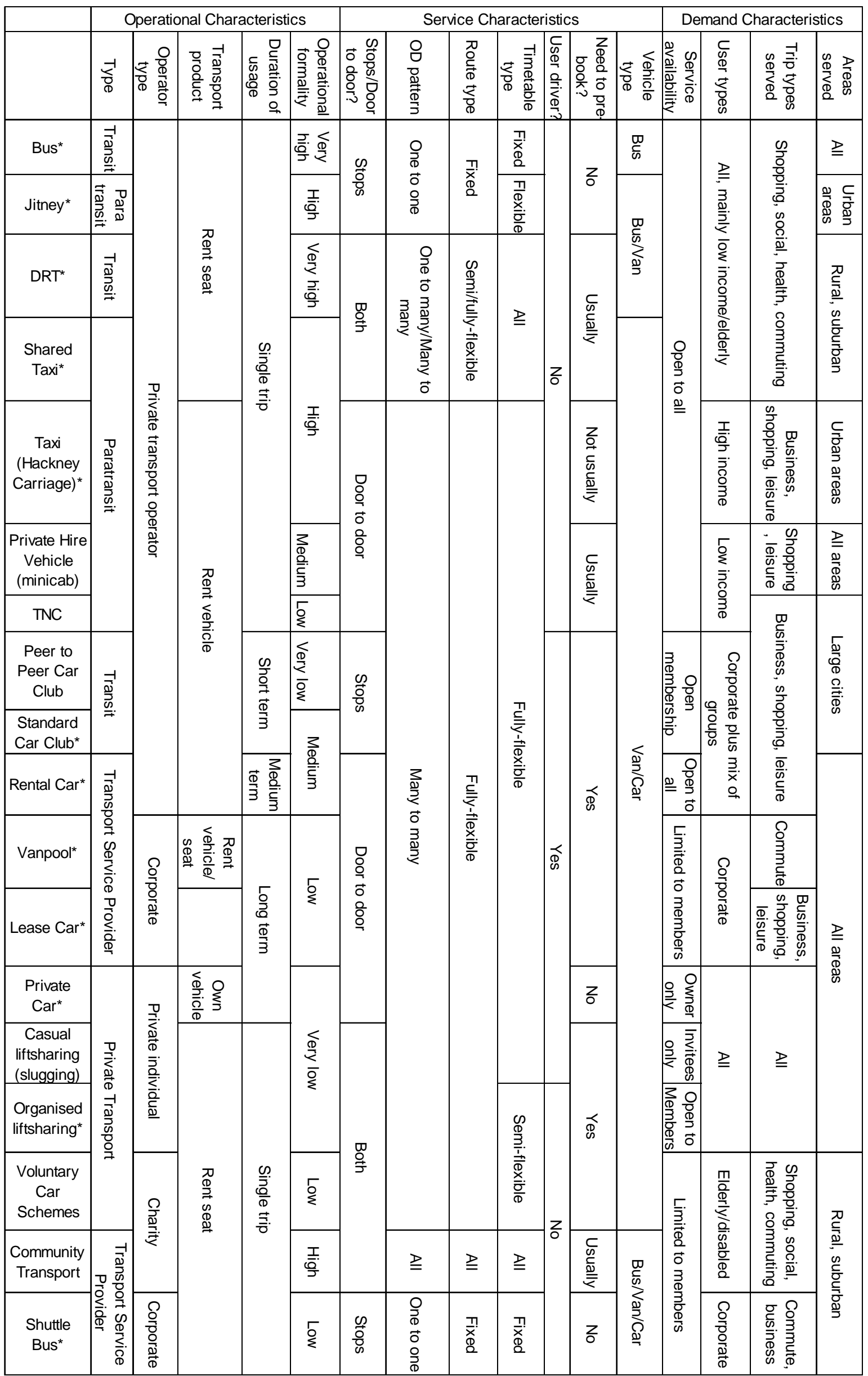

Table 2: Intermediate local transport modes and characteristics (compiled from information in Vuchic, 2007, chapter 2). Note: Modes marked with an * feature later in Figure 1. 
For instance car clubs (short term car rental schemes and known by the term 'car sharing' outside of the UK) are only now taking off after first being seriously introduced in the early 2000s, with the number of carsharing members and vehicles worldwide both trebling between 2006 and 2010 (from 346,610 to $1,251,504$ and from 11,501 to 31,665 respectively). Whilst this is still only a small minority of drivers and vehicles, it still represents a significant trend, especially when coupled with changes in how car clubs are now beginning to be operated - i.e. by large multinational transport concerns (Shaheen and Cohen, 2013). Interestingly this analysis was also supported by several car club operators at the 2012 RAC Foundation Event, where optimism that car clubs would continue to grow and indeed accelerate, was high ${ }^{5}$. There was also a thread around the "rapidly developing range of complementary pay-as-you-go motoring options" that emerged, which suggested to attendees that the sector was about to undergo a significant change in how it operates.

Next, DRT schemes are once more threatening to become commonplace after 'false dawns' in the 1970s and around the turn of the Millennium. In a worldwide review, Enoch et al, 2004 identifies a whole range of DRT types (from Jitneys to shared taxis to semi and fully-flexibly operated minibuses), some of which were addressing the bureaucratic, economic and technical hurdles which had formerly inhibited growth. Meanwhile one message from the 2012 ATCO DRT Workshop, was that DRT services were sometimes replacing conventional bus services, being a more costeffective way of meeting local needs.

Focusing on schemes where cars are shared for journeys, one outcome of the 2013 Carplus Seminar, was that the sector in the UK was now sufficiently advanced to require a standards body and a code of practice to help monitor it. Taking a US perspective, official liftshare (or ridesharing) programmes are again making headlines following previous highpoints in the 1970s (Amey, 2010), as are less formal lift sharing (slugging) arrangements (Chan and Shaheen, 2012), which have now entered a phase of 'technology-enabled ridesharing'.

\section{A theoretical perspective}

To understand how the convergence process may occur, the technological cycles model was felt to closely fit the empirical evidence. This characterises the pattern of evolution as comprising relatively quiet periods of multiple incremental advances and social equilibrium that are occasionally disrupted by rare and unpredictable (i.e. radical) technological innovations (Dokko et al, 2012).

One aspect of this concerns the differences between an incremental and a radical innovation (Abernathy and Utterback, 1978), although a refinement of this instead suggests that paradoxically many innovations are actually 'micro-radical', such that "technological change occurs through rather discrete steps... [meaning] there is a 'discrete-continuum' of technological change" (Durand 1992: p.372). Meanwhile a second aspect relates to the dominant factors involved in implementing an innovation, i.e. 'technology-push', where innovation is determined by the emergence of a new technology, and 'market or demand-pull', whereby the needs of the market create a space for a new innovation to be created. Here, Coombs and Richards (1994) builds on previous work to conclude that "Schumpeterian [i.e. technology-push] processes are more likely to be important at the birth of an industrial sector but are progressively moderated by Schmookler [i.e. demand-pull] processes with time" (p.187).

It therefore seems clear from the literature on the process of innovation that several (albeit relatively loose) observations can be said to apply.

First, innovations take place on a continuum from incremental to radical. Second, oftentimes innovations occur in discrete steps on a 'discrete-continuum' of technological change, whereby one radical innovation is then succeeded by a series of micro-radical and incremental innovations, before the emergence of another radical step. Third, the main drivers behind the adoption of an innovation can be illustrated on a spectrum from being fully due to 'technical-push' factors to being fully caused by 'demand-pull' factors. Fourth, technology-push processes are more likely to be important for a new product initially, but are progressively moderated over time by demand-pull processes. Fifth, both dimensions may be related in that technology-push factors particularly influence radical innovations whilst demand-pull factors perhaps correspond more to delivering incremental innovations.

\footnotetext{
${ }^{5}$ It should be noted that subsequent UK experiences have been mixed, with CityCarClub making a profit for the first time in a decade of operations in 2013, but with Whipcar and car2go having exited the marketplace in 2013 and 2014 respectively (Carplus 2013; Car2go 2014).
} 
Overall the technological cycles approach has been criticised in particular due to its focus on the battles surrounding the adoption of the next dominant innovation product (Dokko et al, 2012). However, it nevertheless performs a useful role in this context by providing a checklist for ensuring that major issues are addressed. The following section therefore applies these observations to the data gathered on the transport sector.

\section{The factors pushing towards a system change}

In answering why these emergent modes are apparently all growing now, it is necessary to look at some wider changes occurring in society.

\section{1 'Technology-push' factors for change}

Recently, technology has significantly changed societies, and often in ways that have yet to be realised. Thus the widespread adoption of the internet, smartphone and GPS tracking technology has revolutionised how people access and use existing transport modes, how they conduct the activities that they need to travel to and from primarily through the provision of real time information, and how transport services are supplied to meet those needs (Banister and Stead, 2004). Next, significant research effort is now focused on propelling vehicles and on new vehicle construction methods (Cairns and Alberto, 2010; Gilbert and Perl, 2007; Cole and Sherman, 1995). Lastly is the shift towards increasingly autonomous vehicles (Sturges, 2012), whereby drivers are steadily being replaced through features such as automatic transmission, anti-lock breaking, adaptive cruise control, automatic braking, and automatic parking in steps from No-Automation (Level 0) to Full Self-Driving Automation (Level 4), via Function-Specific Automation (Level 1), Combined Function Automation (Level 2), and Limited Self-Driving Automation (Level 3) (NHTSA, 2013).

In picking out the most radical innovation, the author's opinion is that this will occur with the change from vehicles where a human driver is required, to one where the vehicle is able to operate independently. This is for several reasons, not least potentially substantial operational cost savings, (drivers account for roughly half in bus and taxi sectors CPT, 2013; personal communication with local taxi operator, 4 September 2013). In addition, replacing drivers would lead to enhanced fuel efficiency, increased network capacity (by allowing vehicles to travel faster and much closer together); and reduced road traffic accidents, most of which are caused by driver error. Finally, people currently excluded from driving by reasons of cost, disability, lack of a licence or a car would benefit from improved access. Clearly, only when sufficient progress has been made in areas to do with control, navigation and obstacle detection could the radical innovation of fully automated vehicles occur, and then these would likely emerge only for particular niches, certainly in the first instance.

Of course these developments would be unlikely to happen in isolation, and will indeed be dependent to some degree on additional drivers from the 'demand-pull' side.

\section{2 'Demand-pull’ drivers for change}

From a political perspective, the global economic recession has led to swingeing cuts being made to public spending in many countries. This has had both direct effects such as reductions in capital investment in infrastructure (now being reversed in some cases), and cuts in revenue budgets affecting subsidies for socially necessary bus services; as well as various indirect effects caused by cutting other public sector services (BBC, 2010). Unsurprisingly perhaps, such subsidy reductions have tended to make the traditional model of providing the bus seem less attractive and hence less viable in many areas, with the result that alternatives such as DRT and shared taxis have been increasingly adopted. Similar effects have arguably also been a by-product of political moves to deregulate certain policy sectors (such as planning for example), and the ideal of promoting 'choice' as a means of driving up service quality (for example in schools and healthcare). On the other hand, concerns about climate change and energy security have pushed governments towards 'encouraging' people not to use their cars wherever possible, through increasing fuel taxes for example.

Institutional changes are also occurring within the intermediate transport mode supplier sector. One aspect recognised at the 2013 BVRLA Seminar, was that the previously distinct leasing and rental sectors are becoming 'increasingly blurred', whilst there is also an increasing range (and use) of 'new mobility solutions' taking place. This is important, because rental and leasing companies accounted for $48 \%$ of all new cars sold in the UK in 2011. Additionally, multi-national transport corporations are now investing in the new intermediate modes. For instance, rental car provider Avis Budget bought out car sharing operator Zipcar to expand its market reach (BBC, 2013), (12 years after Budget withdrew its backing from the Edinburgh car sharing scheme because it was 
(then) financially unsustainable (Hope, 2001)). And car manufacturer BMW launched DriveNow, a point to point carsharing service, in partnership with car rental firm Sixt in June 2011 (see Ip.drivenow.com).

Various projects have also sought to better integrate (particularly public) transport options to create a more user friendly transport system. This is being done spatially and temporally, whereby physical interchanges and timetabling are increasingly being designed to accommodate multimodal traveller needs - e.g. InterConnect in Lincolnshire, UK sees DRT buses deliberately linking up in market towns with the interurban bus network to allow a greater range of destinations for the passenger (Enoch et al, 2006); financially, where ticketing products such as the National Dutch OV chip kaart smartcard (the replacement to the Strippenkaart) now allow users to travel across the Netherlands using multiple operators on a single upfront payment (Jacobs, 2010); and with regards to information - where online 'portals' are being developed to provide relevant information both before and during a journey (see www.transportdirect.info). Perhaps most importantly, integration is also being attempted at the (local) institutional level, whereby seat brokerage systems are being developed to match a user to any appropriate vehicle that is available and in the vicinity at the desired time of travel, as in Somerset, UK for example (Enoch et al, 2006).

Next, more social influences include demographic factors such as the rising proportion of elderly people, who will presumably reach an (increasingly stringent) medically informed cut off point where they are no longer able to drive, yet who will continue to demand mobility options of a standard that is closer to the car than to existing public transport services. At the opposite end of the age spectrum, younger people are likely to continue to be increasingly excluded from car ownership and use through ever more demanding driving tests and rising insurance premiums, as well as attitudinal factors (Delbosc and Currie, 2013). There is also a new culture of 'collaborative consumption', whereby material possessions such as power tools, as well as houses and cars (see www.earthshare.org) - are being lent and borrowed (2013 Carplus Seminar). Meanwhile attitudes to issues such as privacy are also continuing to develop (Cruikshanks and Waterson, 2012).

Economic factors (not least the global economic recession) have also heavily impacted on economic growth, and therefore on the demand for goods and services, employment levels, and purchasing power (Stiglitz, 2010), and hence on travel demand (e.g. DfT, 2013a), (although traffic levels have actually risen slightly overall) (DfT, 2013c). Additionally, rising transport costs were recognised as a crucial driver in pushing shared mobility options (2012 RAC Foundation Event; 2013 Carplus Seminar).

From the demand-pull factors listed, the likely result is a series of incremental developments, due mostly to the fact that for the most part these are fairly steady, long-term pressures.

Crucially, all have implications for how people and goods are moved.

\section{A Four-Step Model to Modal Convergence}

Figure 1: The convergence of local passenger transport modes (see next page) 


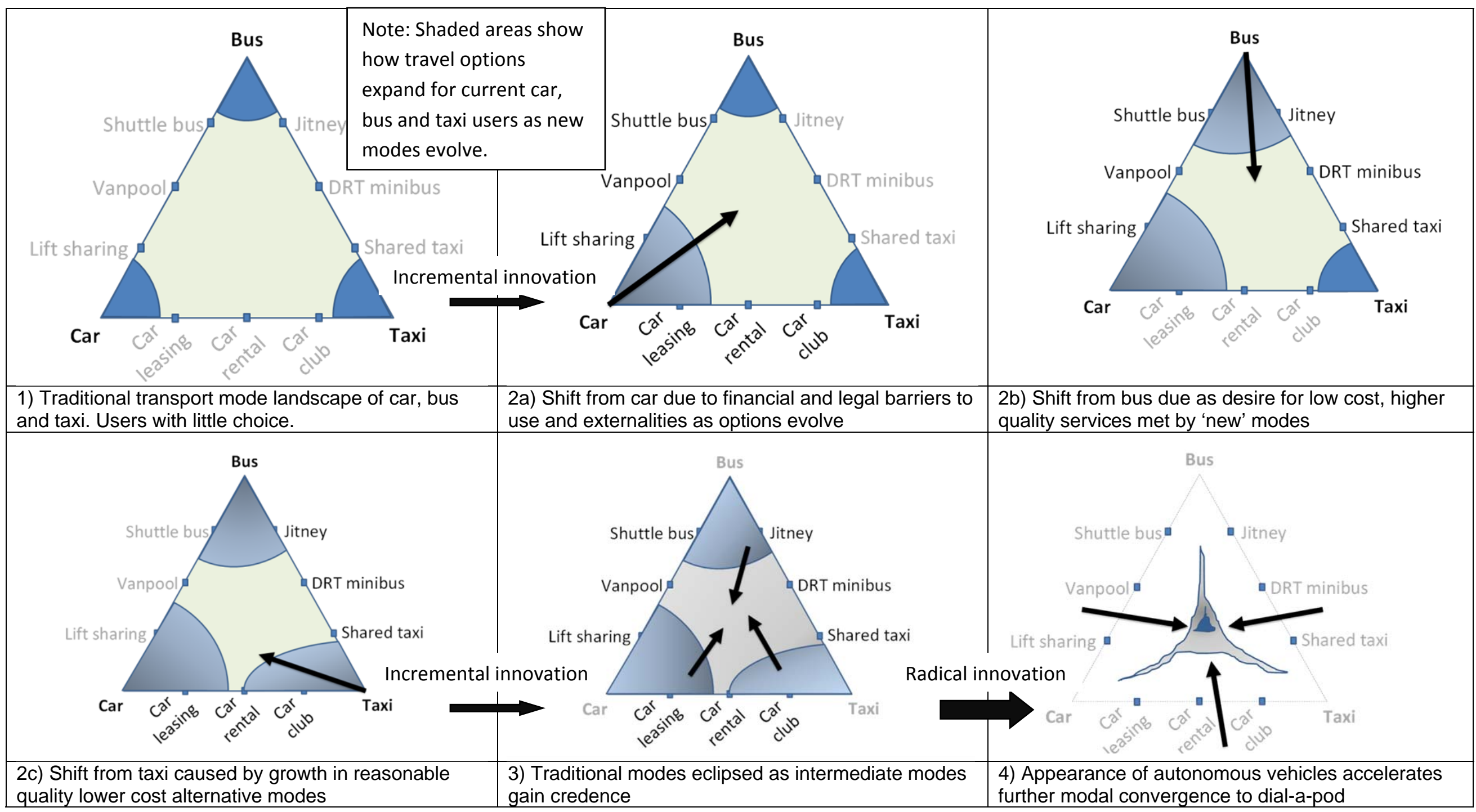


From both the technology-push and demand-pull factors outlined, four Steps are underway that point to a new way of supplying and using local transport (see Figure 1).

Step 1 - The traditional bus, car, taxi landscape.

Step 1 comprises the traditional local transport mode landscape of bus, car and taxi.

Step 2 - The retreat from the traditional modes begins

Next, the second step sees three parallel trends occurring, which here are labelled $2 a, 2 b$ and $2 c$.

In Step 2a, several factors see falling car use - or at least a fall in individual car ownership towards systems more like the bus where either the car is shared for particular trips, or else more like a taxi where the vehicle is 'rented' for particular trips.

Under Step $2 b$, a growing desire for a higher quality travel experience draws people from buses onto modes that offer (almost) demand responsive and (near) door-to-door services in smaller vehicles (i.e. closer to a car or taxi) yet still at a reasonably low price, made possible by recent developments in ICT.

Meanwhile Step 2c shows almost the corollary of Step 2b, where people will use (expensive) taxis less often in their current form as new 'lower fare' modes of a 'reasonable enough' quality begin to become available (e.g. shuttle bus and shared taxi services).

Overall, Step 2 would ultimately see the transport landscape fragment into a large number of different modes - some of which would be in a strong position to develop further, some less so.

\section{Step 3 - The traditional modes are eclipsed by the intermediate modes}

In Step 3 the surviving intermediate modes, now matured, begin to replace the traditional options by being better able to meet user needs and so occupying positions near the centre of the 'modal triangle'.

\section{Step 4 - Modal convergence is accelerated due to appearance of automated vehicle technology}

Up to Step 4, it is expected that any innovations would happen incrementally. But the consolidation of modal characteristics may well accelerate as fully autonomous vehicle technology makes the driver role redundant. Specifically, the local passenger transport landscape looks set to be superseded by a single new mode - a form of automated universal taxi system. Such a system or 'dial-a-pod', would perhaps comprise two seat vehicles which may or may not be capable of being physically linked together to allow larger 'cabins' to be created for larger travelling groups and/or luggage to be carried. Presumably too, they would be electrically powered with batteries being charged by inductive loops in the road and/or at parking places. In terms of the user experience meanwhile, one expectation is that the passenger would press a 'call' button (from a smartphone or TV screen) and select a destination, plus desired departure/arrival time, fare level and any other pertinent details. In this regard, there could be scope for different 'attribute packages' being provided to passengers where premiums might be charged for peak-time and door-to-door services, while discounts may be available for people willing to share cabins with strangers, booking in advance, or for being flexible about waiting and/or departure times. Such a system could, in theory, provide a high quality service at reasonable cost, and without the need for ownership or driving qualifications, and therefore be very attractive for people to use on a day to day basis.

\section{Summary}

Summarising this, while Step 2 is seemingly already underway, the progression to Step 3 is obviously less certain. This is largely due to a series of forces acting in opposition to the trends already identified (to be explored in Section 7). In particular, it may be that the market forces are not strong enough to topple the existing order of how transport services are delivered. Similarly, the progression to Step 4 may well not be as smooth as indicated here should fully autonomous vehicles prove to be more difficult to introduce than anticipated here.

\section{Issues preventing change.}

Of course there are many barriers to such huge changes in transport supply and use, especially to fully autonomous vehicles. On the technology-push side, these include:

- Implementation issues. For instance, the expectation is that there would likely be (possibly significant) periods of overlap in how the steps come about, meaning that anticipated network benefits may not be initially realised (Anderson et al., 2014). Such overlaps may also result uncertainty, with possible impacts on investment decisions for example. For 
instance, how sensible would it be to invest in a new light rail line if people are to be offered a system like a dial-a-pod in 10-15 years which would render it obsolete?

- Next, there may be delays in addressing the remaining technological barriers to full automation, which could have implications if, for example a sub-optimal technology is chosen as a result.

On the demand-pull side meanwhile, barriers may include:

- Public resistance. There are likely to be fears about the safety of unmanned systems (Thierer and Hagemann, 2014), and about security (relating to automated cars being 'hacked' for example) (Anonymous, 2014). There may also be concerns about a perceived loss of freedom, (if drivers are no longer being allowed to drive or if the transport system could potentially exert a significant level of control over how, when and where people travelled) (Lyon, 1994).

- Political resistance would revolve around overcoming the bureaucratic hurdle of how to plan, operate, finance, insure and regulate a 'new mode' given the complexity of existing arrangements (Enoch et al, 2004), and about trade union concerns over changing job roles (as when London Underground proposed introducing automated metro services for example) (BBC, 2012).

- Economic issues. Anderson et al (2014) notes that economic disruption from the adoption of autonomous vehicles would be "considerable" (p.39). Key questions here centre on who would pay to introduce and operate such a system; how much would they pay; and how and when would they pay? And what would the wider costs be to society as a whole?

- Social impact. Typically certain societal groups - such as the poor, elderly, young adults, ethnic minorities, mobility impaired, rural residents, the car less, and women - tend to benefit to a lesser degree and more slowly from 'improvements' than other members of society (Anderson, et al. 2014), not least because of the initial high cost of new ICT and car-based technologies (Fagnant, 2013).

- Environmental effects. Efficiency gains in the use of land, fuel, materials, and vehicles could be expected from an automated system (Fagnant, 2013). Yet efficiency gains often see people, businesses and society more generally readjusting their lifestyles/processes to maximise their economic pay off, possibly into still longer distance trips and even more dispersed development (Fagnant et al, 2014).

There is also a (strong) argument that suggests that the benefits of modal specialisation (especially at the level of individual stakeholders) are simply too strong to be swept away by an entirely new system and that consequently other modes will evolve and survive in a different form - and this is of course possible and even likely. On the other hand, one might argue that there have been modes in the past that did largely dominate (if not quite fully eclipse) all others at different points in history - such as the horse until the mid- $19^{\text {th }}$ century, and the railways for seventy years after that (Garrison and Levinson, 2014).

\section{Implications for policy makers and practitioners}

Overall, change is already occurring and could well become more rapid as time goes by. In other words, a paradigm shift away from the traditional model to a (potentially substantially) modified transport system architecture in the next decade or two looks to be a possibility, and one that ought to be considered. Moreover, as demonstrated by the change from horse to car 100 years ago, such a shift, once initiated after sufficient barriers have been removed, could well take place in a relatively short time. This is for three key reasons in particular.

First, as was the case a century ago when motorised transport replaced the horse, relatively little modification of the infrastructure would be required. Such 'legacy effects' can otherwise be significant where new systems are introduced (Garrison and Levinson, 2014). Second, automation elements are already being added to mostly newer and higher priced vehicles meaning that people are already becoming used to automated parking, antilock brakes and cruise control for example, while autonomous vehicle developer Google is already testing a prototype on the roads and expects to have a commercially available variant ready within 3-5 years, though regulators are somewhat more cautious (Keane, 2013). Third, even if a major change is required in vehicle technology requiring entirely new vehicles to be introduced, the average lifespan of a new car is only around 15 years, meaning that the majority of the car parc could be 'naturally' switched within a 20 year period. Indeed, even the expectation of the UK Department for Transport is that there will be a mixed autonomous/semi-autonomous/manual vehicle fleet in place by 2040 (DfT, 2013b) - a body not normally credited with having an overactive imagination!

However, though an automated-style 'dial-a-pod' system may well deliver significant benefits to society, it will also present new challenges to deal with. For example, Hall (2012), Fagnant and 
Kockelman (2014), Garrison and Levinson (2014) and MacKenzie et al (2014) note a range of possible impacts emerging. These could include more dispersed development leading to more travel overall - people could live further from their workplaces without the stress of driving, and children could be ferried to schools without the need to be escorted; less parking spaces and street signs would be required; there would be far fewer traffic accidents (meaning less need for hospital beds for victims); and more jobs for electronics manufacturer employees, but far less work for drivers, traffic enforcement officers and vehicle insurance sellers.

There are also implications for the future viability of other modes and facilities such as bus stations, park-and-ride sites, light rail routes, and even potentially for high speed rail and airport expansion schemes. For example, if people can choose to use a form of dial-a-pod that offered a private cabin on a demand responsive and door-to-door basis for a reasonable price, then would they really decide to travel by a light rail service, and so why invest in such systems? Similarly, for the freight sector, it is possible to note some parallel developments occurring, particularly as relating to a shift towards modal and operator convergence, and towards the vehicle fleet already becoming increasingly autonomous. Also, should local transport become autonomous then why not interurban transport too? Briefly speculating on the future of international trips meanwhile, one could see air travel, with all of its user discomforts and negative societal impacts, being replaced with some form of vacuum tube fitted on an elevated track or even attached to the sea bed, through which some form of pod could be 'fired' at very high speed between countries and continents. Indeed, such fantastic sounding schemes have already been proposed, most recently the Hyperlink idea connecting Los Angeles and San Francisco by entrepreneur Elon Musk (SpaceX, 2013).

Finally there are implications for transport research. In the short term, perhaps the most crucial question relates to quantifying the degree to which individual users and non-users, operators, business and society more generally might benefit (or dis-benefit) from such a system should it materialise. In other words, is such a system desirable, and if not then how could we either modify it so that it becomes so? Then there are system issues to be explored around:

- System design: what exactly the system would look like; and how it would work?

- Implementation: how it would be introduced - incrementally along-side existing transport systems or separately?

- Operation: how it would be organised, managed, priced, funded, regulated, licensed, taxed, and insured?

- Stakeholder involvement: what organisations would be involved? When? How?

- User responses: how would users respond to such a system, and what would the implications be for each of the previous research questions?

In the meantime one presumes that studies on traditional transport modes would need to be adapted to take account of the changed transport landscape.

\section{Conclusions}

The potential benefits promised by new ICT solutions and ever more autonomous vehicles coupled with the inability of the current transport system to meet current (never mind future) demands and the aforementioned broader societal trends, suggest the possibility of local passenger transport radically changing in the relatively near future should not be discounted.

Specifically, this paper suggests that the 'traditional' local transport landscape of the bus, taxi and private car may now be beginning to change in a way that has not occurred for a century.

These developments are being driven by both technology-push and demand-pull factors including: the development of the internet, smartphones and locational trackers and the increasing automation of the motor vehicle; the perceived threats of climate change, energy security, the global economy and the idea of increased choice; the goals of reducing public spending and of mitigating congestion levels; and demographic factors such as an ageing population and suburbanisation; changing attitudes towards issues such as sustainability, working, privacy and ownership.

The resulting model suggests that the domination of the car, taxi and bus will steadily decline towards a future where a range of new intermediate modes first mature and then supersede them. Next, the emergence of fully autonomous vehicles would accelerate this modal convergence process, such that a single automated, universal taxi or dial-a-pod service, of higher quality than the bus, yet cheaper than the taxi, and not requiring driving skills of the traveller, would emerge as the primary local passenger transport mode. 
From a policy perspective, clearly there are many positive implications from such developments, particularly in terms of cost reduction and improved system efficiency. However, there may well be other less welcome consequences too, which will need to be identified, planned for and managed.

Overall, the significance of the research problem rests on the fact that policy makers and practitioners are planning for the future on the assumption that the way that transport is supplied and used will not significantly change in the medium term. Yet the evidence of history along with a range of on-going societal trends indicates that such an assumption is inherently flawed. Thus, we all need to wake up and realise that the world around us is rapidly changing and that as a consequence the transport system (and the associated activities relating to operations, planning, policy and research) will need to change too.

\section{References}

Abernathy, W. J. and J. M. Utterback. 1978. Patterns of industrial innovation, Technology Review, 80(7), 41-47.

Amey, A., 2010. Innovations in ridesharing, TDM Review, 17(1), 21-22.

Anderson, J. M., Nidhi, K., Stanley, K. D., Sorensen, P., Samaras, C. and O. A. Oluwatola. 2014. Autonomous Vehicle Technology: A Guide for Policymakers, Santa Monica, CA: RAND Corporation.

Anonymous, 2014. Can Your Car Be Hacked?, Mission Critical, 4(1), 15, February. Visit http://issuu.com/auvsi/docs/mc/17?e=0/6564626 [Accessed 1211 2014].

Banister, D. and D. Stead. 2004. Impact of information and communications technology on transport, Transport Reviews, 24(5), 611-632.

Barth, M. and S.A. Shaheen. 2002. Shared use vehicle systems: Framework for classifying carsharing, station cars and combined approaches, Transportation Research Record, 1791, 105112.

British Broadcasting Corporation (BBC). 2010. Spending Review 2010: Key points at-a-glance, http://www.bbc.co.uk/news/uk-politics-11591881 [Accessed 19 August 2013].

British Broadcasting Corporation (BBC). 2012. Strike ballot over tests for driverless Tube trains, http://www.bbc.co.uk/news/uk-england-london-19741282. [Accessed 19 August 2013].

British Broadcasting Corporation (BBC). 2013. Avis to buy Zipcar vehicle sharing firm for $\$ 500 \mathrm{~m}$, http://www.bbc.co.uk/news/business-20890174. [Accessed 19 August 2013].

Cairns, E.J. and P. Alberto. 2010. Batteries for electric and hybrid-electric vehicles, Annual Review of Chemical and Biomolecular Engineering, 1, 299-320.

Carplus. 2013. Whipcar closes its doors and City Car Club makes a profit, Shared Mobility News, Spring, $\quad$ http://www.carplus.org.uk/archived newsletter/shared-mobility-news-spring-2013/. [Accessed 7 July 2014].

Car2go. 2014. Closure of Car2go and withdrawal from UK market, http://www.car2go.com/en/birmingham/. [Accessed 7 July 2014].

Chan, N.D. and S.A. Shaheen. 2012. Ridesharing in North America: Past, present and future, Transport Reviews, 32(1), 93-112.

Chernick, J. and S.A. Shaheen. 2014. Innovations in Shared Use Mobility and Transportation Demand Management: Trends and Policy Updates, Workshop Session at the 93rd Annual Meeting of the Transportation Research Board, Session 137, Committees of Transportation Demand Management, Intelligent Transportation Systems, Managed Lanes, and Emerging and Innovative Public Transport and Technologies, Transportation Research Board, National Academy of Science, 12-16 January, Washington DC.

Cole G. S. and A. M. Sherman. 1995. Light weight materials for automotive applications, Materials Characterization, 35(1), 3-9.

Confederation of Passenger Transport UK. 2013. CPT cost index 2013, CPT, London, 30 June, http://www.cpt-uk.org// uploads/attachment/2716.pdf [Accessed 6 November 2013].

Coombs, R. and A. Richards, 1994. Technologies, products and firms' strategies: A framework for analysis, (in eds. Rhodes, E. and Wield, D.) Implementing new technologies: Innovation and the management of technology, London: Blackwell, 186-211. 
Cruikshanks, S. and B. Waterson. 2012. Will privacy concerns associated with future transport systems restrict the public's freedom of movement? Procedia - Social and Behavioural Sciences, 48, 941-950.

Davison, L.J., M.P. Enoch, T.J. Ryley, M.A. Quddus and C. Wang. 2012. Market niches for DRT, Research in Transportation Business and Management, 3, 50-61.

Delbosc, A. and G. Currie. 2013. Causes of youth licensing decline: A synthesis of evidence, Transport Reviews, 33(3), 271-290.

Department for Transport (Great Britain). 2013a. National Travel Survey 2012, London: Department for Transport, 30 July.

Department for Transport (Great Britain). 2013b. Transport - an engine for growth, London: Department for Transport, August.

Department for Transport (Great Britain). 2013c. Road traffic estimates for Great Britain: Quarter 2 2013, London: Department for Transport, 8 August.

Dokko, G., Nigam, A. and L. Rosenkopf, 2012. Keeping steady as she goes: A negotiated order perspective on technological evolution, Organisation Studies, 33(5-6), 681-783.

Durand, T. 1992. Dual technological trees: Assessing the intensity and strategic significance of technological change, Research Policy, 21, 361-380.

Enoch M P, Potter S, Parkhurst G and Smith M T (2004) Exploratory Assessment of and Innovations in Demand Responsive Transport Services - Intermode, Final Report, Department for Transport and Greater Manchester Passenger Transport Executive, London, April.

Enoch M P, Ison S G, Laws R and Zhang L (2006) Evaluation Study of Demand Responsive Transport Services in Wiltshire, Wiltshire County Council, Trowbridge, Wiltshire, July.

Fagnant, D. J. 2013. The future of fully automated vehicles: Opportunities for vehicle-and ridesharing, with cost and emissions savings, PhD Thesis, University of Texas, Austin TX.

Fagnant D.J. and K. Kockelman. 2014. Preparing a Nation for Autonomous Vehicles: Opportunities, Barriers, and Policy Recommendations for Capitalising on Self Driven Vehicles, Poster presentation at the 93rd Annual Meeting of the Transportation Research Board, Paper 14-1281, Session 697, Current Research Findings on Vehicle-Highway Automation Systems, VehicleHighway Automation Committee, Transportation Research Board, National Academy of Science, 12-16 January, Washington DC.

Garrison, W.L. and D.M. Levinson. 2014. The Transportation Experience, Oxford: Oxford University Press.

Gilbert, R. and A. Perl. 2007. Grid-connected vehicles as the core of future land based transport systems, Energy Policy, 35, 3053-3060.

Hall, P. 2012. Fruitcake fantasy or technological turning point? Town and Country Planning, 81, 415-416.

Hope, S. 2001. Monitoring and evaluation of the Edinburgh City Car Club, Edinburgh: Scottish Executive Central Research Unit.

Jacobs, B. 2010. Architecture is politics: Security and privacy issues in transport and beyond, Data Protection in a Profiled World, Springer, 289-299.

Keane, A.G. 2013. Self driving cars more Jetsons than reality for Google designers, Bloomberg, 6 February, http://www.bloomberg.com [Accessed 19 August 2013].

Lyon, D. 1994. The Electronic Eye: The Rise of Surveillance Society, Cambridge: Polity Press.

Lytton L and Postyn T (2012) Car Rental 2.0: New alternatives to car ownership, London: RAC Foundation, November.

MacKenzie, D.W., Z. Wadud and P.N. Leiby. 2014. First Order Estimate of Energy Impacts of Automated Vehicles in the United States, Poster presentation at the 93rd Annual Meeting of the Transportation Research Board, Paper 14-2193, Session 697, Current Research Findings on Vehicle-Highway Automation Systems, Vehicle-Highway Automation Committee, Transportation Research Board, National Academy of Science, 12-16 January, Washington DC.

Millard Ball, A. 2005. Carsharing: Where and how it succeeds, TCRP 108, Transit Cooperative Research Program, Washington DC: Transportation Research Board. 
Morris, E. 2007. From horse power to horsepower, Access, 30, Spring, 2-9.

Mowery, D. and N. Rosenberg, 1979. The influence of market demand upon innovation: A critical review of some recent empirical studies, Research Policy, 8, 102-153.

National Highway Traffic Safety Administration (United States). 2013. US Department of Transportation Policy on Automated Vehicle Development, p4. 30 May. Visit http://www.nhtsa.gov/About+NHTSA/Press+Releases/U.S.+Department+of+Transportation+Releas es+Policy+on+Automated+Vehicle+Development. [Accessed 11 November 2014].

Nutley, S. 1988. Unconventional modes of transport in the United Kingdom - A review of types and the policy context, Transportation Research A, 22(5), 329-344.

Shaheen, S.A. and A.P. Cohen. 2013. Carsharing and personal vehicle services: Worldwide market developments and emerging trends, International Journal of Sustainable Transportation, 7(1), 5-34.

Shladover, S. E. 2000. Progressive Deployment Steps Leading Toward an Automated Highway System, Transportation Research Record. 1727. 54-161.

SpaceX. $2013 . \quad H y p e r l o o p \quad A l p h a, \quad$ August, http://www.spacex.com/sites/spacex/files/hyperloop alpha-20130812.pdf. [Accessed 12 August 2013].

Stiglitz, J. 2010. Freefall: Free markets and the sinking of the global economy, London: Penguin.

Sturges, D. 2012. Beyond the personal automobile, MIT Technology Review, 31 January, http://www.technologyreview.com/news/426743/beyond-the-personal-automobile/ [Accessed 19 August 2013].

Thierer, A.D. and R. Hagemann., 2014. Removing Roadblocks to Intelligent Vehicles and Driverless Cars, Wake Forest Journal of Law and Policy, forthcoming.

Vuchic, V.R. 2007. Urban transit: Systems and technology, Englewood NJ: Wiley.

Zmud, J., L. Ecola, P. Phleps and I. Feige. 2013. The future of mobility: Scenarios for the United States in 2030, Institute for Mobility Research, Santa Monica, CA: RAND Corporation.

\section{Biography}

Dr Marcus Enoch joined Loughborough University as a lecturer in Transport Studies in 2003 and became a senior lecturer in 2007. Previously he worked at the Open University and at the journal Local Transport Today. Dr Enoch has a research interest in investigating the impact of context, governance and policy interventions on transport systems. 